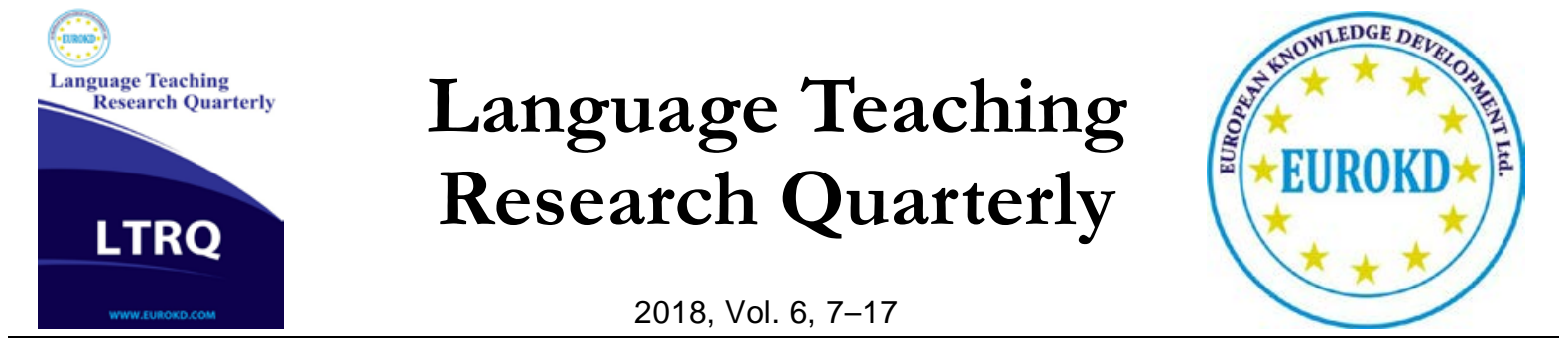

\title{
Fostering Foreign Writing Accuracy through Teachers' Scaffolding of the Iranian Learners: The Case of Gender
}

\author{
Sedigheh Amini*, Sara Shabani \\ Islamic Azad University, Sari, Iran
}

\begin{abstract}
Received 2 November 2017 Accepted 4 April 2018

The present study attempted to compare teacher's corrective feedback on the intermediate EFL male and female learners in L2 writing accuracy. To this aim, 45 out of 65 EFL students participated in this study. They were selected through an Oxford Placement Test (OPT) among thirty learners. After giving OPT, 45 intermediate learners who scored one SD above and below the mean were excluded from the study. Three groups were selected: 15 male learners, 15 female learners and 15 male and female learners in the control group. The instrument was writing pre-and post-tests. Two experimental groups had teacher-student interaction conferencing for their classrooms. The conferences were based on the Aljaafreh and Lantolf's regulatory scale (1994) in conferencing session. The learners' errors were dealt with three grammatical structures: a) articles ( $\mathrm{a}-\mathrm{an}-$ the $-\Theta)$, b) past tense, and c) past progressive. In two weeks later, both of experimental groups revised their writing tasks. The result of this study was that interactional corrective feedback improved learners' writing accuracy. The improvement of language learners in writing accuracy was appeared in the number and the length of interactional turns. Moreover, the result indicated that three groups had significant difference and the first null hypothesis of the study was rejected. Moreover, the male learners outperformed than female group in the interactional turns, but there was no significant difference between male and female learners in interactional turns. This study provided few implications for language teachers and curriculum developers such as providing interactional practices among language learners and teachers.
\end{abstract}

Keywords: Error, Corrective Feedback, Interactional Conferencing, Gender, Sociocultural Perspective 


\section{Introduction}

Errors and correcting them have been taken into account as the basic themes in second/foreign language acquisition and teaching in the last decades. Corrective feedback (CF) is also considered as a way to correct and solve students' errors in grammar, pronunciation and so on. Iwashita (2003) states that although CF is a complicated process and realm, it should be emphasized because this process assists teacher to analyze different ways in correcting learners and find the more appropriate ways. The significance of the present study was on the comparative study of teacher's corrective feedback on the intermediate EFL male and female learners in L2 writing accuracy. Corrective feedback is recognized as vital in second or foreign language learning and teaching in two last decades, because the learners require the acceptance or rejection of their responses. The importance of working on error correction is associated with increasing in research on form-focused instruction (Doughty \& Williams, 1998). Formfocused refers to a kind of instruction in which linguistic form is drawn attention by the learners (Ellis, 2000).

A large number of studies about the effectiveness, and the importance of CF have been carried out in second/foreign language acquisition (Kheradmand Saadi \& Saadat, 2015; Rezazadeh, Tavakoli \& Abbasi Rasekh, 2015). For example, Kheradmand Saadi and Saadat (2015) studied the effect of direct and metalinguistic written corrective feedback on Iranian EFL learners' grammatical knowledge. The result showed that the grammatical knowledge of the learners in both groups developed as a result of the two types of feedback; nonetheless, there was not a statistically significant difference between the students' performance on the grammar test before and after the treatment. Moreover, Rezazadeh, Tavakoli and Abbasi Rasekh (2015) conducted a study to observe the effectiveness of two types of written feedback as direct corrective feedback and metalinguistic explanation on Iranian EFL learners' implicit and explicit knowledge of English definite and indefinite articles. The results revealed that both treatments were effective in the immediate posttests.

One of the main problems of EFL students is that learners have a large amount of problems in correcting their errors in grammar that are committed in speaking and writing skills. Therefore, this can be important to know how to treat these errors. Another striking problem is that language instructors in EFL contexts and especially in Iran cannot recognize the most appropriate form and the best time of correcting learners' errors. To bridge the abovementioned gaps, the present study compared teacher's corrective feedback on the intermediate EFL male and female learners in L2 writing accuracy.

Based on the above-mentioned purposes of the present study, the following research questions were formulated:

1) Do teacher's interactional corrective feedback practices improve students' writing accuracy?

2) Do teacher's interactional corrective feedback practices make any significant difference in male and female students? 


\section{The Empirical Studies about Corrective Feedback (CF) Practices}

Amirghassemi (2015) studied on the effects of scaffolded CF on EFL learners' accurate use of articles and past tenses in writing. The results revealed that the efficacy of CF is much reliant on the type of error to be corrected. Whereas no significant difference was found between the two groups in using articles, the Scaffolded CF group significantly outperformed the Reformulation group in using past tenses. Implicit in this finding is that, for certain categories, providing extensive feedback may hardly take any effect and simpler feedback types will suffice.

Yousefi (2015) studied the patterns of corrective feedback and negotiated feedback present in senior-level adult ESL classrooms. The data were collected through actual classroom observations (audio-taped) and follow-up interviews. The findings of this study showed that based on classroom observations and transcribing the data, the most frequent type of corrective feedback was 'clarification request', which comprises 8 (32\%) feedbacks out of 25 and the least frequent feedback was 'explicit correction' receiving no consideration.

Rezazadeh, Tavakoli and Eslami Rasekh (2015) investigated the effects of two types of written feedback - direct corrective feedback (DCF) and metalinguistic explanation (ME) - on Iranian EFL learners' implicit and explicit knowledge of English definite and indefinite articles. Assigned to three groups of DCF, ME, and control groups, the participants took four tests in three testing phases: pretest, posttest, and delayed posttest. Results indicated that both treatments were effective in the immediate posttests. However, the ME proved to have longer lasting effects than the DCF as the improvement of both knowledge types were sustained after a three-week period in the ME group.

Akbarzadeh, Saeidi and Chehreh (2014) studied the effect of Oral Interactive Feedback (OIF) on the accuracy and complexity of Iranian intermediate EFL learners' writing. After ensuring the homogeneity using Preliminary English Test (PET), the researchers randomly assigned 50 sophomores into OIF group and Explicit Feedback (EF) group, with 25 students in each of them. The participants in the OIF group received oral interactive feedback, including elicitation and metalinguistic clues, on their written errors, while those in the EF group received oral explicit correction on their written errors. Data collection was based on immediate revisions of compositions and a post-test. Using ANCOVA, the researchers found that the OIF group outperformed the EF group in terms of both accuracy and complexity in both revised compositions and post-test.

Leontjev (2014) investigated on the effect of automated adaptive CF. The present study attempts to contribute to the existing research on corrective feedback from this perspective by comparing the effects of two types of automated CF on learning: adaptive feedback (i.e., feedback incrementally adapting to learners' abilities by becoming more explicit and detailed) and knowledge of response feedback. The participants were learners of English randomly assigned to two groups, receiving either adaptive feedback (experimental group) or knowledge of response feedback (control group). The findings indicate a significantly higher positive effect of the adaptive CF. Furthermore, the experimental group considered the feedback to be 
significantly more useful for learning than the control group although there was not a clear difference between the two groups' perceived usefulness of the feedback for getting the answers right during the intervention.

Mustafa (2012) studied on the Saudi ESL learners' opinions about writing feedback based on socio-cultural perspective. This qualitative study employed informal conversational interviews and semi-structured individual interviews. The findings suggest that the Saudi students do not think highly of the feedback, and that the feedback they desire is markedly different from what they receive. The students mentioned several impediments to feedback. From a sociocultural perspective, the feedback practices do not adhere to the best practices of the theory, resulting in major hindrances to the students’ learning/writing development.

\section{Methodology}

\section{Participants}

60 intermediate EFL students participated in this study. They were selected through an Oxford Placement Test (OPT) among thirty learners. After giving OPT, 45 intermediate learners who scored one SD above and below the mean were excluded from the study. Three groups were selected: First experimental group: 15 intermediate male learners, and 15 intermediate female learners. 15 participants were embedded in a control group (males and females) that were taught in the traditional method (an ordinary method). This process was performed in four weeks. Their age range was between 15 to 20 years old.

\section{Instruments}

To tap participants' level of English language proficiency level, an Oxford Placement Test (2001, Syndicate) was utilized to homogenize the participants in the study. The test consisted of reading, vocabulary and grammar sections. The second instrument was writing pre- and post-tests. A picture description task was used for pre- and post-tests. 6 sequential pictures for each story were selected for the all participants to write a story. Those pictures were printed and given to the learners individually. The teacher asked the participants to describe what they saw in the pictures. Those pictures were scrambled and the teacher asked to the participants to unscramble those pictures. The topic of the story was "an old man".

\section{Procedures}

At first, the teacher explained about the cluster and the procedure to prepare that in the classroom in two sessions. All students were given 6 sequential pictures and were supposed to write a story for the pretest. In the first session, the experimental groups wrote a writing task. In the next sessions, the teacher tried to help language learners individually based on the determined scale. The teacher corrected their writing task based on their grammatical errors and she provided corrective feedback in terms of Aljaafreh and Lantolf's regulatory scale (1994) in correcting session. The learners' errors were dealt with three grammatical structures: 
a) articles ( $a-$ an - the $-\Theta)$, b) past tense, and c) past progressive. After correcting learners' errors, the learners wrote the story again. In two weeks later, both of experimental groups revised their writing tasks. The teacher checked their activities.

In the next part, the control group used a traditional method. In this group, the teacher taught the learners and gave the instruction in a traditional procedure. For traditional form, there was no feedback and revision. This group wrote a story about those given pictures. Both groups were supposed to describe a series of pictures for posttest.

\section{Result}

To answer the first question which seeks the effectiveness of the teacher's interactional corrective feedback practices on students' writing accuracy, Shapiro-Wilk test of normality was first used to check the normality of the pre-test data and the results are presented on Table 1.

In table 1, the male and female learners' errors in writing task were analyzed based on ShapiroWilk normality test.

Table 1

Tests of Normality results for Writing Pre-test

\begin{tabular}{lll}
\hline \multicolumn{2}{l}{ Shapiro-Wilk } & \multicolumn{2}{l}{ Sig } \\
\hline Statistic & Df & .066 \\
\hline .911 & 15 & .229 \\
.939 & 15 & .670 \\
.965 & 15 & \\
\hline
\end{tabular}

a. Lilliefors Significance Correction

*. This is a lower bound of the true significance.

The null hypothesis of normality test maintains that there is no significant difference between the population and the sample. As the results in Table 1 demonstrate, the values of $P$ for both Shapiro-Wilk tests of normality for the results of Students' pre-scores data were found to be larger than .05; thus, the null hypothesis for the total results was not rejected. In other words, there was not a significant difference between the sample and the population for the total results. This meant that the data did show normal distribution, and therefore, one of the conditions to use parametric tests was established. Accordingly, One-way ANOVA is used to compare the means of three groups. Table 2 shows the descriptive statistics of writing pre-test. 
Table 2

\begin{tabular}{llll}
\multicolumn{3}{c}{ Descriptive Statistics of Writing } & pre-test $(N=15)$ \\
\hline & Mean & Variance & Std. Deviation \\
\cline { 2 - 4 } EG1 (Male)-Pre-test & 21.45 & 3.208 & 1.791 \\
EG2 (Female)-Pre-test & 22.05 & 2.997 & 1.731 \\
CG-Pre-test & 19.89 & 2.322 & 1.523 \\
Valid N (listwise) & & & \\
\hline
\end{tabular}

As revealed in the Table 2, the three groups had the following mean and standard deviation: first experimental group (male) $(X=21.45, S D=1.791)$; second experimental group $(X=22.05 ; S D=1.731)$ and the control group $(X=19.89 ; S D=1.523)$. As it can be seen, the mean of the three groups in the pre-test is different. Accordingly, One-way ANOVA is used to compare the means of three groups in Table 3.

Table 3

One-way ANOVA Writing pre-scores

\begin{tabular}{llllll}
\hline & Sum of Squares & $d f$ & Mean Square & $F$ & Sig \\
\hline Between Groups & 3.633 & 2 & 1.819 & .635 & .534 \\
Within Groups & 163.100 & 42 & 2.861 & \\
\hline Total & 166.733 & 44 & & \\
\hline
\end{tabular}

The analysis Table 3 reveals that there was no significant difference $(\boldsymbol{p}=\mathbf{. 5 3 4}>\mathbf{. 0 5})$ between the performance of first experimental, second experimental and control groups in writing accuracy pre-scores. Table 4 presents Shapiro-Wilk test of normality to check the normality of the post-test data.

Table 4

Tests of Normality results for Writing Posttest

\begin{tabular}{llll}
\hline \multicolumn{4}{c}{ Shapiro-Wilk } \\
\hline Groups & Statistic & $d f$ & Sig \\
\hline EG1 & .892 & 15 & .029 \\
EG2 & .971 & 15 & .773 \\
CG & .939 & 15 & .249 \\
\hline
\end{tabular}

a. Lilliefors Significance Correction

The null hypothesis of normality tests holds that there was no significant difference between the population and the sample. As they are shown in the Table 4, the values of $P$ for Shapiro-Wilk tests of normality for the results of learner's writing posttest data were found to be larger than .05; the null hypothesis for the total results was not rejected. In other words, there was a significant difference between the sample and the population for the total results. This meant that the data did show normal distribution, and as such, one of the conditions to 
use parametric test was established. One-way ANOVA is used to compare the means of three groups.

Table 5 shows the descriptive statistics of writing posttest scores.

Table 5

Descriptive Statistics of Writing post-test

\begin{tabular}{lcccc}
\hline & $N$ & Mean & Variance & Std. Deviation \\
\hline EG1 (Male)-Post & 15 & 18.60 & 3.621 & 1.902 \\
EG2 (Female)-Post & 15 & 16.75 & 4.092 & 2.022 \\
CG-Post & 15 & 12.52 & 4.374 & 2.091 \\
Valid N (listwise) & 15 & & & \\
\hline
\end{tabular}

As revealed in Table 5, the descriptive statistics of the three groups: first experimental group ( $X=18.60, S D=1.902)$; second experimental group $(X=16.75 ; S D=2.022)$ and the control group ( $X=12.52 ; S D=2.091)$. As it can be seen, the mean of the three groups in the post-test is different. Accordingly, One-way ANOVA is used to compare the means of three groups in Table 6.

Table 6

One-way ANOVA Writing post-scores

\begin{tabular}{lccccc}
\hline & Sum of Squares & $d f$ & Mean Square & $F$ & Sig. \\
\hline Between Groups & 54.233 & 2 & 27.117 & 6.794 & .002 \\
Within Groups & 227.500 & 42 & 3.991 & & \\
\hline Total & 281.733 & 44 & & & \\
\hline
\end{tabular}

The analysis Table 6 reveals that there was a significant difference $(p=.002<.05)$ between the performance of first experimental, second experimental and control groups in writing accuracy after the instruction. For observing the differences between groups in post-test scores, Table 7 was presented as Tukey HSD.

Table 7

Multiple Comparisons Writing post-scores Tukey HSD

\begin{tabular}{llccccc}
\hline & & & & & \multicolumn{2}{c}{ 95\% Confidence Interval } \\
\cline { 5 - 7 } (I) Groups & (J) Groups & Mean Difference & Std. Error & Sig. & $\begin{array}{c}\text { Lower } \\
\text { Bound }\end{array}$ & $\begin{array}{c}\text { Upper } \\
\text { Bound }\end{array}$ \\
\hline EG1(Male) & EG2 & $1.850^{*}$ & 63.176 & .051 & .329 & 3.370 \\
& CG & $2.150^{*}$ & 63.176 & .003 & .629 & 3.670 \\
EG2(Female) & EG1 & $-1.850^{*}$ & 63.176 & .051 & -3.370 & -.329 \\
& CG & .300 & 63.176 & .883 & -1.220 & 1.820 \\
& EG1 & $-6.150^{*}$ & 63.176 & .003 & $-3.67 \mathrm{C}$ & -.629 \\
& EG2 & -.300 & 63.176 & .883 & $-1.82 \mathrm{C}$ & 1.220 \\
\hline
\end{tabular}

*. The mean difference is significant at the 0.05 level. 
Table 7 showed the differences between three groups. In this regard, there was a significant difference between L1-mediated, L2-mediated and the control group in writing accuracy. This table showed that EG1 outperformed than EG2 and CG. There was no significant difference between EG1 and EG2, however.

\section{Second Question}

To investigate the second null hypothesis expressing that "teacher's interactional corrective feedback practices do not make any significant difference in male and female students", The Paired t-test was used to determine if there are statistically significant differences between the male and female groups of independent variables in pre-writing task.

Table 8

Paired Samples t-test of Male and Female Groups in Writing Pretest

\begin{tabular}{|c|c|c|c|c|c|c|c|c|c|}
\hline \multicolumn{10}{|c|}{ Paired Differences } \\
\hline & & \multirow[t]{2}{*}{ Mean } & \multirow[t]{2}{*}{ Std. } & \multirow{2}{*}{$\begin{array}{l}\text { Std. } \\
\text { Error }\end{array}$} & \multicolumn{2}{|c|}{$\begin{array}{l}\text { Interval of the } \\
\text { Difference }\end{array}$} & \multirow[t]{2}{*}{$\mathrm{t}$} & \multirow[t]{2}{*}{ df } & \multirow[t]{2}{*}{ Sig. } \\
\hline & & & & & Lower & Upper & & & \\
\hline Pair 1 & $\begin{array}{l}\text { Male-pretest - } \\
\text { Female-pre-test }\end{array}$ & .38462 & 2.06311 & .57220 & -1.63134 & .86211 & .672 & 29 & .071 \\
\hline
\end{tabular}

The results of the paired-sample t-test of the learners' performance on writing pre-test is presented in Table 8 . As the sig ( 2 tailed) is higher than .05 , it can be stated that the mean difference from the pre to the post-test is not significant. In this regard, the performance of learners in writing post-test should be calculated through Paired t-test.

Table 9

Paired Samples t-test of Male and Female Groups in Writing Post-test

\begin{tabular}{|c|c|c|c|c|c|c|c|c|c|}
\hline \multirow[b]{4}{*}{ Pair 1} & \multicolumn{9}{|c|}{ Paired Differences } \\
\hline & & \multirow[t]{2}{*}{ Mean } & \multirow{2}{*}{$\begin{array}{c}\text { Std. } \\
\text { Deviation }\end{array}$} & \multirow{2}{*}{$\begin{array}{l}\text { Std. } \\
\text { Error }\end{array}$} & \multicolumn{2}{|c|}{$\begin{array}{l}\text { 95\% Interval of } \\
\text { the Difference }\end{array}$} & \multirow[t]{2}{*}{$\mathrm{t}$} & \multirow[t]{2}{*}{$\mathrm{df}$} & \multirow[t]{2}{*}{ Sig. } \\
\hline & & & & & Lower & Upper & & & \\
\hline & $\begin{array}{l}\text { Male-pretest - } \\
\text { Female-pre-test }\end{array}$ & 29852 & 2.06887 & .42110 & -1.63134 & .86211 & .510 & 29 & .055 \\
\hline
\end{tabular}

The results of the paired-sample t-test of the learners' performance on writing post-test is presented in Table 9. As the sig (2 tailed) is higher than .05, it can be stated that the mean difference from the pre to the post-test is not significant. In this regard, the second null hypothesis is supported.

\section{Discussion}

This section discusses the results of this study in order to answer the research questions. The current study examined the differential effects and potential benefits of the teacher's corrective 
feedback on the writing skill between the male or female learners. The findings showed that the teacher assisted their participants as the experimental groups linguistically and cognitively in the process of feedback negotiation. As the results indicated, the total number of the errors and also the related errors which the experimental groups made in the revision writing task decreased to half in comparison to the first writing task. This comparison was justified due to the fact that both writing's had the same topic with the same focused grammatical points.

Another interesting point was that step by step the noticing level of the experimental groups increased. Based on the Lantolf's views (2000), interaction and social context mediate language learning and in this study, teacher's continuous mediation with procedural implicitexplicit feedback had positive effect not only on noticing the errors but also in terms of the number of errors they made.

The findings of this showed that they were in line with that of Nassaji and Swain (2000) who set out their study in line with Aljaafreh and Lantolf's (1994) study, which was about the contingency of scaffolding in learners' ZPD. According to the Nassaji and Swain's study, they worked with two groups of Korean adult learners and just focused on the use of definite and indefinite articles in English. For one group they applied implicit feedback to the written assignment at the beginning and in the case that the learner did not find the error, progressively more explicit feedback was provided for the learner until the learner could correct the error.

They argued that scaffolding was done based on the ZPD of the learner. In other words, the other group used random explicit or implicit feedback. At the end of their study, the first group of learners outperformed the second group who just received random explicit or implicit feedback. They claimed that their study was "consistent with the Vygotskian socio-cultural perspective in which knowledge is defined as social in nature and is constructed through a process of collaboration, interaction, and communication among learners in social setting and as the result of interaction with the ZPD” (Nassaji \& Swain, 2000, p. 49).

Generally, all the participants in the experimental groups had a good progress in correcting errors. Taking the individual learners into consideration in this study rather than focusing on the total number of errors of all students, five participants demonstrated fewer errors in the revision assessment compared to the writing task which is again a support for what is mentioned above. Students number 2 and 5 (male learners) and 1, 7 and 8 (female learners) had a better performance in correcting the errors in the revision assessment. In general, this can be concluded that this gradual correction procedure had an impact on these specific learners' performance across writing tasks. Of course, one point should be reminded is that some intervening factors such as the attitude of the learners, classroom setting and fatigue may have had an effect on their different performance in their writing and correcting the errors. Furthermore, the type of grammatical errors might also be a factor. It means that grammatical points differ in terms of difficulty for different learners. Some grammatical structures can be more difficult for the learners to learn and they might need more help.

The difference in using corrective feedback practices showed the difference between the experimental groups and the control group. This was in line with Zarei (2010) study which was 
about the relationship between corrective feedback practices and gender. Based on this study, using corrective feedback practices had a significant relationship with gender. This shows that gender can influence on the process of corrective feedback. Furthermore, Hajimohammadi (2010) studied the impact of self-reflection on learners in EFL writing progress. In his study, the finding also showed that the learners who received corrective feedback in grammatical errors had better performance than the control group, and this result is in line with the current study.

Another important finding to be discussed is that is the number and the length of turns in the interactional practices among the teacher and the experimental groups. The results showed that the number and the length of turns in the male leaners was more than in the female learners. The finding was in line with Singer's (1984) study which was about the role of males and females in education. According to that study, males are more sociable and better risk-takers and finally they tend to speak more than females. In this study, the male learners attempted to speak more than the female learners for correcting their errors.

\section{Conclusion}

This present study investigated to compare teacher's corrective feedback on the intermediate EFL male and female learners in L2 writing accuracy. The findings showed a significant difference between the experimental groups to correct the grammatical errors in writing ability. The results also showed that the learners who received direct corrective feedback from the teacher performed significantly better than those in the indirect and no corrective feedback groups. As regards the gender, it was revealed that students' gender had a significant impact on students' writing ability in which males outperformed females. On the whole, it was observed that the students' writing ability was affected by direct corrective feedback and gender. The results are consistent with Bitchener's (2012) findings who found that direct corrective feedback by the teacher seemed to be the best corrective feedback method. She also stated that direct CF by the teacher was the most preferable method among the students.

In addition, the performance of experimental groups was better than the control group. Chandler (2003) had also found students in the experimental group that received feedback, significantly outperformed those in the control group.

\section{References}

Akbarzadeh, R. Saeidi, M., \& Chehreh, M. (2014). The effect of oral interactive feedback on the accuracy and complexity of EFL learners' writing performance: uptake and retention. Iranian Journal of Language Teaching, 2(2), 105-126.

Aljaafreh, A. \& Lantolf, J.P. (1994). Negative feedback as regulation and second language learning in the zone of proximal development. Modern Language Journal, 78 (4), 465 483. 
Amirghassemi, A. (2015). The effect of scaffolded vs. non-scaffolded written corrective feedback on EFL learners' written accuracy. World Applied Sciences Journal, 22(2), 256263.

Bitchener, J. (2012). Written Corrective Feedback for L2 Development: Current Knowledge and Future Research. TESOL QUARTERLY 46 (4), 855 - 860.

Ellis, R. (1994). 'A theory of instructed second language acquisition', New York: Oxford University Press.

Ellis, R. (2000). Task-Based Research and Language Pedagogy. Language Teaching Research, 4, 193-220.

Hajimohammadi, R. (2010). Impact of Self-Correction on Extrovert and Introvert Students in EFL Writing Progress, English Language Teaching, 4, 161-168.

Iwashita, N. (2003). Negative feedback and positive evidence in task-based interaction: differential effects on L2 development. Studies in Second Language Learning, 2(3), 12-23.

Johnson, K. (2010). Second language teacher education: A sociocultural perspective. NewYork: Routledge Publication.

Mustafa, R. F. (2012). Feedback on the feedback: Sociocultural interpretation of Saudi ESL learners' opinions about writing feedback. English Language Teaching, 5(3), 3-15.

Nassaji, H. \& Swain, M. (2000): A Vygotskian perspective on corrective feedback: The effect of random versus negotiated help on the learning of English articles. Language Awareness. 9 (1), $34-51$.

Rezazadeh, M., Tavakoli, M., \& Eslami Rasekh, A. (2015). The Effects of direct corrective feedback and metalinguistic explanation on EFL learners' implicit and explicit knowledge of English definite and indefinite articles. Journal of English Language Teaching and Learning, 16, 113-146.

Zarei, D. (2010). Teaching ESL/EFL writing beyond language skills. A paper presented at $3^{\text {rd }}$ International Annual LATEFL China Conference, Tonghua, China. 